\title{
Docentes Abriendo las Puertas del Clóset: Narrativas de Resistencias y Apropiaciones a la Heteronormatividad en Profesores Homosexuales/Lesbianas en Escuelas Públicas y Privadas de Santiago de Chile
}

\author{
Teachers Opening the Closet Door: Narratives of Resistances \\ and Heteronormativity Appropriations in Gay/Lesbian \\ Teachers in Public and Private Schools in Santiago of Chile
}

\author{
Mario Catalán Marshall * \\ Universidad de Chile, Chile
}

\begin{abstract}
La investigación buscó analizar bajo una perspectiva feminista y queer, el cómo los y las docentes homosexuales y lesbianas significan sus vivencias relacionadas a su sexualidad, cuerpo y género, frente a los discursos y prácticas heteronormativos presentes en las instituciones escolares ubicadas en la ciudad de Santiago de Chile. Para llevar a cabo la investigación, se utilizó la técnica de entrevista biográfica (a 7 profesores (auto) identificados como homosexuales/gays y 3 profesoras (auto) identificadas como lesbianas), las que fueron analizadas bajo una metodología de carácter cualitativa. Dentro de los principales resultados que aquí se exponen, se destacan: las características del vivir-se en la escuela como profesor/a homosexual y lesbiana, y se describen los miedos y silencios que rondan la cotidianeidad de sus vidas; las (im)posibilidades de vivir-se como profesor homosexual y lesbiana de manera visible; y el rol agenciable de muchos/as docentes frente a la heteronormatividad existente en las instituciones escolares, abriéndose a partir de sus narrativas, nuevas interrogantes que nos permiten ampliar la discusión respecto a la situación, necesidades y expectativas de los profesores homosexuales y lesbianas en el sistema escolar chileno.
\end{abstract}

Descriptores: Resistencia a la opresión; Sexualidad; Estereotipo sexual; Pedagogía; Escuela.

\begin{abstract}
This research looks to analyze, using a queer and feminist epistemology, the meanings of being lesbian/gay teacher in the Chilean school system, and how their lives, bodies, sexuality and gender are affected by the heteronormative practices and dialogs in the school system. For methodological proposes, biographical interviews were used (seven teachers self-identified as homosexual ore gay, and three teachers self-identified as a lesbians) thru a qualitative methodology. Within the main findings of this research we are given an insight into the life lesbian/gay professors face in the school system and we describe the fear and silences that surround their daily lives. Also, shown in the research is how possible or impossible it is to live a visible open life as a lesbian/gay professor. Lastly, the research exposes the role many professors take, thru their pedagogical practices, to create spaces where they can resist and disrupt the heteronormative culture of the school system. These professors' narratives open an array of questions and discussions regarding the situation how professors live in the Chilean school system and the needs and expectations they have of this system.
\end{abstract}

Keywords: Resistance to oppression; Sexuality; Gender stereotypes; Pedagogy; School. 


\section{Introducción}

Teniendo presente que las instituciones escolares, están signadas por el mandato regulador de los cuerpos, las sexualidades y las distintas expresiones de género, y siendo dichas instituciones, el lugar en donde se pone en práctica una paradoja evidente, entre el actual discurso de aceptación y respeto hacia las diversas expresiones del ser, sentir y pensar, en contraposición con la transmisión de manera no oficial, pero no así menos evidente, de una serie de rituales, símbolos, lenguajes, imágenes, comportamientos y conocimientos, que irían constituyendo a los sujetos desde de una verdadera matriz normalizadora, la que silencia a la vez, a todos aquellos sujetos que no se ajustan a ella (lesbianas, gays, bisexuales, travestis, transexuales, intersexuales).

Es a partir de esta situación, que considero que la escuela como institución, irá contribuyendo a la instalación de una norma o matriz (hetero)normativa, dentro de los cuerpos y subjetividades de los diversos sujetos presentes en ella (Butler, 2001), promoviendo y reproduciendo a través de los espacios y experiencias de socialización generados en ésta, el silenciamiento e ignorancia hacia determinadas expresiones de deseo e identificaciones de género (Sedgwick, 1998). Desde esta perspectiva, el silencio e ignorancia producidos en la escuela hacia las sexualidades no heterosexuales, no son parte de un accidente casual, sino que son parte de la misma matriz de (hetero)normalización que reproduce a las sexualidades validadas y aceptadas (Butler, 1982, 2001, 2005; Foucault, 1976).

Así, al no hablarse oficialmente de homosexualidad en la escuela, se estaría garantizando la promoción de la norma, silenciando obligatoriamente a todos los cuerpos, tanto de estudiantes, como de docentes que se encuentren fuera del binarismo normativo de feminidad y masculinidad aceptados (Flores, 2008; Ramos, 2007). Respecto a esta problemática, el objetivo principal de esta investigación fue analizar las prácticas de sociabilidad de los/las docentes homosexuales y lesbianas frente a la matriz heteronormativa que reproducen las instituciones escolares. Para ello, se propuso a partir de una perspectiva epistemológica feminista y queer (Harding, 1987; Haraway, 1995; Córdova, 2011), acércanos a las narrativas de un grupo de profesores homosexuales y lesbianas que se dedican al ejercicio de la docencia en distintos establecimientos escolares de la ciudad de Santiago de Chile, interiorizándonos en cómo ellos/as relataron el vivir su sexualidad, su cuerpo y su género dentro de las instituciones escolares en donde actualmente trabajan y/o trabajaron, y evidenciar también, el cómo la heterormatividad que existe hoy en día dentro de las instituciones escolares, condiciona o no sus vidas y su ejercicio profesional.

El propósito de encontrar respuestas a esta problemática, va de la mano con la finalidad de desmontar y subvertir el conocido prejuicio que se ejerce cotidianamente contra los sujetos LGBTIQ dedicados a la docencia escolar, en donde según los diversos antecedentes recopilados para fundamentar esta investigación (en su mayoría internacionales, localizados en el nortegeopolítico) se desplegaría sobre ellos, una verdadera matriz cultural que tiene como pilares fundamentales, el distanciamiento y pánico moral, en donde se equipara al sujeto homosexual/lesbiano a la anormalidad, el delito, promiscuidad, perversión, peligro y riesgo de contagio, extendiéndose la interrogación, sanción e indeseabilidad hacia los cuerpos de los y las docentes identificados como no heterosexuales dentro del espacio escolar (Ferfolja, 2015; King, 2004; Lecky, 2009; Movilh, 2008; Smith, Wright y Esposito, 2008; Tonya, 2015; Wright, 2010). 


\section{Territorialidades heteronormativas en la escuela}

Como sujeto homosexual y profesor por profesión, no soy ajeno a esta investigación, los supuestos y objetivos formulados en ella, tienen que ver directamente con mi recorrido vivencial dentro de las instituciones escolares, en donde muchas veces viví en carne propia, las dificultades del tener que adaptarme a la norma y a lo esperado para un profesor dentro de la escuela. Normas que desde mis experiencias me hicieron dar cuenta, que el ser profesor homosexual o profesora lesbiana vendría a ser un conflicto dentro de la cotidianeidad escolar actual, conflicto que consideré, no puede ser algo netamente personal, sino que también sería compartido por diversos sujetos homosexuales y lesbianas dedicados a la profesión docente. Bajo esta realidad personal y compartida me situé, ocupando los postulados del feminismo como herramienta epistemológica y metodológica, y recurriendo a distintos autores que se ubican dentro de lo que hoy se conoce como teoría queer, para así, poder dar entendimiento y análisis a los principales resultados obtenidos. Desde ahí, y mediante una perspectiva Foucaultiana, analizamos los discursos asociados a las vivencias de profesores homosexuales y lesbianas, en sus términos de productividad, interiorizándonos en cómo las prácticas y discursos de poder (Foucault, 1976), han incidido en la producción de sus mismos cuerpos y subjetividades (sexualidad como efecto de una tecnología de saber-poder)

La investigación consideró también, a la heterosexualidad, no como una práctica u orientación sexual del deseo más, sino como una expresión históricamente construida y conceptualizada de la sexualidad humana, que se impone a todos los órdenes culturales existentes como un régimen construido de verdad, normalidad y de valoraciones jerárquicas, que niega toda posibilidad de existencia a las vidas y cuerpos que no respondan a las imposiciones de su régimen, y que a la vez, necesita a su otro par opuesto (La Homosexualidad) para su existencia y naturalización continua (Butler, 2001; Rich, 1996; Rubin, 1989; Wittig, 1992). Michael Warner, sintetiza parte de los planteamientos de las autoras citadas, mediante la introducción del concepto de heternormatividad, el cual, según su definición, se refiere a las diversas prácticas de regulación social que concurren a hacer de la correspondencia entre sexo biológico, expresión social de género y preferencia sexual, como la norma (Warner y Berlant, 2002). De esta manera, al emplear el concepto de heteronormatividad en esta investigación, se pretende contribuir a la desnaturalización de la heterosexualidad. En este sentido, dicho concepto nos permitirá problematizar desde una mirada amplia, compleja y sobre todo política, la supuesta normalidad y naturalidad de la heterosexualidad como matriz de ordenamiento social impositivo y omnipresente.

Se estableció dentro de la investigación, que las escuelas en la actualidad, están dominadas por un discurso heteronormativo, debido a que en ellas se crean y recrean formas de pensar, signados por los mandatos de los saberes dominantes que cada sociedad determina como legítimos y que son a la vez reproductoras del orden social masculino (Bourdieu, 2000, 2005). Así, se consideró que los discursos legítimos que circulan en La Escuela, convertirían a ésta, en un lugar en donde se gobierna, controla, vigila y disciplina a los cuerpos, las sexualidades y subjetividades de las personas, organizándose el espacio escolar, como un sutil, pero verdadero instrumento de represión y control (Foucault, 1976). Estos discursos respecto a la sexualidad se han ido articulando a través de las diversas prácticas pedagógicas puestas en práctica en la modernidad, bajo las distintas teorías y enfoques de la didáctica. 
Ante esto, Morgade (2008), indica que los modelos pedagógicos expandidos históricamente, han orientado las prácticas docentes a tal punto de producir lo que ella señala como la pedagogización del cuerpo, tanto de estudiantes, como también, de profesores/as. Por lo tanto, será la escuela, una de las instituciones en donde se aprendería a utilizar el cuerpo (Esteban, 2004), pero no bajo cualquier modalidad, sino que se aprendería en función del sexo/género correspondiente a cada uno/a, bajo la lógica de lo masculino o femenino signado por la heterosexualidad binaria como la norma valida y correcta a seguir, en sintonía a la vez, con la orientación heterosexual del deseo sexualamoroso, lo cual es considerado también, como lo esperable y lo normal (Britzman, 2002).

\section{Método}

Ya que el objetivo de la investigación fue analizar los mecanismos de sociabilidad de los y las docentes homosexuales y lesbianas, frente a la matriz heteronormativa, promovida por las instituciones escolares, mediante la recolección de sus propias narrativas de vida; se volvió necesaria la adopción de una metodología cualitativa, debido a que esta se mueve en el orden de los significados y sus reglas de significación. En este sentido

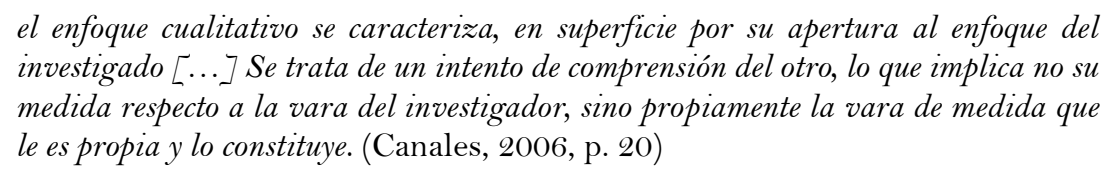

En la investigación adopté un enfoque biográfico-narrativo. Este enfoque puede ser comprendido también como una subárea dentro de la investigación cualitativa, en donde se da prioridad a lo experiencial, en una situación de dialogo interactivo, entre investigador/investigados (Bolívar, Domingo y Fernández, 2001).

Para llevar a cabo las historias de vida, recurrí a la ejecución de una entrevista biográfica, la que se aplicó a los distintos sujetos de la investigación seleccionados (de manera individual). En cada entrevista, se les dio la opción a cada entrevistado/a de elegir un seudónimo y resguardar de esta manera su completo anonimato. Cada una de las entrevistas fue transcrita y se realizó una devolución de ellas a los entrevistados/as, para que estos pudiesen verificar por sí mismos/as, el resguardo de su identidad, y de quererlo, me realizarán las sugerencias que estimasen necesarias para la omisión de esos episodios en donde ellos/as considerasen que se expuso directa o indirectamente su identidad. La cantidad de sujetos a entrevistar, estuvo determinada por el punto de saturación que se generó en el proceso de recopilación de la información, el cual fue determinado al momento de no obtener mayor información relevante a medida que se continuó entrevistando a más sujetos.

Para llegar a los participantes se realizó un muestreo gradual, es decir, se generó un arranque muestral inicial para luego definir la estructura de la muestra, mientras se desarrolló la investigación a partir de un muestreo teórico (Flick, 2007). Teniendo en cuenta esto, a modo de arranque muestral, se contactó a dos participantes que cumplieran con uno o más de los siguientes criterios:

- Personas del sexo masculino y femenino que se autodefinan con una de las siguientes categorías: Homosexual, Gay, Lesbiana.

- Sean profesores(as) titulados. 
- Tener entre 1 a 25 años de experiencia laboral en instituciones escolares como profesor(a) de aula.

- Estar trabajando como profesor(a) de aula en colegios públicos o privados, laicos o religiosos.

- Estar trabajando como profesor(a) de aula en alguno de los siguientes niveles de enseñanza escolar: enseñanza parvularia, enseñanza básica, enseñanza media.

- Vivir en la ciudad de Santiago de Chile.

Los participantes del arranque muestral fueron contactados a través de personas de mi círculo cercano, quienes están vinculados a profesores/as homosexuales y profesoras lesbianas que trabajan actualmente en diferentes colegios de la ciudad de Santiago de Chile y quienes, a la vez, me proveyeron de contactos para sumar a cinco participantes más a la investigación (bajo la modalidad de bola de nieve). Con la finalidad de llegar a más participantes, se redactó una convocatoria que fue publicada en distintas redes sociales, a partir de la cual se incluyeron a tres personas que se contactaron vía correo electrónico para ofrecerse a acceder a un encuentro y concertar una entrevista. De esta forma, la muestra total de esta investigación se conformó a partir de diez participantes, (debido a que con este número de entrevistas se alcanzó la saturación teórica).

A modo de resumen, presento el siguiente cuadro con las principales características de nuestros entrevistados/as.

Cuadro 1. Participantes del estudio

\begin{tabular}{|c|c|c|c|c|c|}
\hline PARTICIPANTES & EDAD & SEXUALIDAD & ProfESIÓN & $\begin{array}{c}\text { AÑOS DE } \\
\text { EJERCICIO } \\
\text { DOCENTE } \\
\end{array}$ & $\begin{array}{l}\text { DEPENDENCIA } \\
\text { ESCOLAR }\end{array}$ \\
\hline Eduardo & 28 & Homosexual & $\begin{array}{l}\text { Profesor de } \\
\text { Lengua } \\
\text { Castellana }\end{array}$ & 6 & $\begin{array}{r}\text { Municipal } \\
\text { (Público) }\end{array}$ \\
\hline Carlos & 31 & Homosexual & $\begin{array}{l}\text { Profesor de } \\
\text { Biología }\end{array}$ & 4 & $\begin{array}{l}\text { Particular } \\
\text { Subvencionado }\end{array}$ \\
\hline Oscar & 32 & Homosexual & $\begin{array}{l}\text { Profesor de } \\
\text { Lengua } \\
\text { Castellana }\end{array}$ & 2 & $\begin{array}{l}\text { Municipal } \\
\text { (Público) }\end{array}$ \\
\hline Alan & 26 & Homosexual & $\begin{array}{l}\text { Profesor General } \\
\text { Básica }\end{array}$ & 2 & $\begin{array}{l}\text { Municipal } \\
\text { (Público) }\end{array}$ \\
\hline Pedro & 28 & Homosexual & $\begin{array}{l}\text { Profesor de } \\
\text { Historia y } \\
\text { Ciencias } \\
\text { Sociales }\end{array}$ & 4 & $\begin{array}{l}\text { Particular } \\
\text { Pagado }\end{array}$ \\
\hline Andy & 31 & Homosexual & $\begin{array}{l}\text { Profesor de } \\
\text { Artes Visuales }\end{array}$ & 6 & $\begin{array}{l}\text { Particular } \\
\text { Subvencionado }\end{array}$ \\
\hline Dimarco & 27 & Homosexual & $\begin{array}{l}\text { Profesor de } \\
\text { Historia y } \\
\text { Ciencias } \\
\text { Sociales }\end{array}$ & 1 & $\begin{array}{l}\text { Particular } \\
\text { Subvencionado } \\
\text { (actualmente } \\
\text { retirado) }\end{array}$ \\
\hline Simone & 25 & Lesbiana & $\begin{array}{l}\text { Profesora de } \\
\text { Inglés }\end{array}$ & 2 & $\begin{array}{l}\text { Municipal } \\
\text { (Público) }\end{array}$ \\
\hline Millaray & 31 & Lesbiana & $\begin{array}{l}\text { Profesora de } \\
\text { Lengua } \\
\text { Castellana }\end{array}$ & 8 & $\begin{array}{l}\text { Particular } \\
\text { Subvencionado }\end{array}$ \\
\hline Violeta & 36 & Lesbiana & $\begin{array}{l}\text { Profesora de } \\
\text { Matemáticas }\end{array}$ & 10 & $\begin{array}{l}\text { Particular } \\
\text { Pagado }\end{array}$ \\
\hline
\end{tabular}

Fuente: Elaboración propia. 


\section{Resultados}

Las siguientes categorías de análisis corresponden al reflejo de un ejercicio reflexivo y de conversación, entre los profesores y profesoras que fueron parte de esta investigación. Con ellas y ellos, recorrimos un viaje en el que transitamos -muchas veces de la mano-, por diversas experiencias, creencias, cuestionamientos, anhelos, pero sobre todo también, emociones y sentimientos. Estas categorías, que se exponen aquí de manera resumida, fueron parte de un ejercicio reflexivo, en donde parte de mis experiencias personales como profesor homosexual y los recorridos de vida de los entrevistados/as, se entrelazaron y dieron como resultado los análisis que aquí daremos cuenta. Dicho esto, cada realidad contextual y situada, crea y recrea las posibilidades y limitaciones a la que los sujetos dicen estar expuestos/as. Lo anterior, es necesario evidenciarlo, debido a que los análisis que aquí se expondrán, no tienen por finalidad el proponer patrones de conducta homogéneos ligados a los profesores/as homosexuales y lesbianas, por lo tanto, no son en ningún caso, generalizables al todo de la población LGBTIQ dedicada al ejercicio docente en Chile. Más bien, las biografías que aquí se posicionan, pueden y deben ser leídas como constataciones de determinadas rutas de vida lésbico/gay, en las que, de manera individual, cada quien (como lector), puede decidir sentirse o no reflejado/a, ya sea desde el espejo mismo que estas vivencias pueden llegar a generar, o desde la posición crítica a construir(nos).

\subsection{El miedo: iSe me nota? temores reales o imaginarios frente al "pasar piola"}

La mayoría de las narrativas de los y las docentes, presentan elementos claros que nos llevan a señalar, la existencia de determinados miedos reales y/o imaginarios, frente al hecho de que su propia sexualidad sea de conocimiento público dentro de las escuelas. Estos miedos, respecto al conocimiento o visibilidad sexual, adquieren muchas veces características diferenciantes, según quien las dice y donde dice percibirlos.

Como primer elemento, se hace presente la existencia determinados discursos sociales en las narrativas de los/as docentes, discursos que reflejan las características de una cultura dominante, a partir de la cual, se recoge la concepción heteronormativa que demarca los límites de lo legitimo/ilegitimo, lo aceptable/despreciable, lo normal/anormal, en términos de comportamiento e identidades sexuales.

En base a estas demarcaciones, la mayoría de los/as profesores homosexuales y lesbianas entrevistados/as, señalan que la identidad del sujeto homosexual/lesbiana estaría siendo aún representada socialmente, como un comportamiento de carácter prohibido, lo que propiciaría en ellos/as, la emergencia de determinados miedos, respecto al hecho de que su sexualidad sea conocida y sancionada dentro de la escuela. Estos miedos, se encontrarían situados a partir de las lecturas que los otros (docentes, directivos, apoderados, alumnos/as) pudiesen llegar a realizar respecto al vínculo de su homosexualidad/lesbianismo con su ejercicio de la profesión docente.

Al inicio tú quieres ser una persona lo más uniforme posible, quieres como encajar dentro del colegio, quieres conseguir el trabajo, quieres mantenerlo, no quieres lidiar con un prejuicio de los demás, entonces, en la primera instancia tú tienes que mantener como ese disfraz po, de persona heterosexual (...) llegar, tratar de ser una persona lo más neutra posible, ;tampoco quería ser el macho "zorrón” del colegio!, pero quería ser lo más neutro posible, quería llamar la atención lo menos posible, cuando empecé como profe...cachai, porque no sabía a qué me enfrentaba. Andy (31 años) 
De lo evidenciado, la figura del sujeto homosexual, estaría contenida dentro de un discurso en donde su existencia sería vista por los demás, con cierto grado de sospecha y cuestionamiento, a partir de un ojo crítico e inquisidor que sitúa a la heterosexualidad como la norma de lo vivible, que delimita y regula a la vez, los comportamientos sexuales que serían válidos y permitidos dentro del espacio escolar (Weeks, 1998). Ante ello, el miedo a lo desconocido, el miedo a los otros y el miedo a lo que pudiesen llegar a pensar, decir y hacer esos otros, contribuiría a la emergencia de una presión social, que muchos docentes dicen interiorizar y corporizar, respecto al tener que desarrollar un determinado tipo de existencia, en donde sus comportamientos (corporalidad) y discursos, estén en sintonía con el binarismo de género masculino/femenino heterosexual.

Es por eso, que, para muchos profesores homosexuales y lesbianas, se les convierte en una necesidad de sobrevivencia, el tener que recurrir a estrategias de mimetización y camuflaje heterosexual, ya sea, a través de lo que ellos/as dicen decir (discursividad), como también, a través de lo que ellos/as dicen hacer (corporalidad), con su cuerpo y performance de género dentro de la escuela.

Estas estrategias, son señaladas por los/as profesores/as, como un mecanismo a poner en práctica, debido a la necesidad que tendrían algunos/as de tener que pasar piola ante los ojos inquisidores y moralizantes de los demás, y evitar así, dentro de lo posible (y de acuerdo a sus propias posibilidades individuales), cualquier manifestación que sea prohibitiva o cuestionadora hacia su existencia como sujeto homosexual/gay/lesbiana dedicado/a al ejercicio docente.

\begin{abstract}
Después de hacer mi práctica ahí, me dijeron que me iban a dejar como profe de historia en el colegio, y ahí me motive y claro, ahí me contrataron al otro año y ahí empezó el tema del cuestionamiento. Porque claro, tu empezai a vincularte con los distintos actores del colegio, ósea más que con los estudiantes, mi primer conflicto fue con mis colegas, yo siempre le preguntaba a mis amigos de fuera del colegio ¿̇se me nota o no se me nota?, y me pasaba ese rollo, ósea el colegio me empezó a "paquear" mi forma de ser. Pedro (28 años)
\end{abstract}

Eduardo (28 años), por su parte, nos comenta cómo en este intento del querer pasar piola, el propio cuerpo puede actuar como limitante, señalando:

En la práctica, siempre entrabamos de a dos, y justo me toco entrar de a uno, y me toco hablar a mí, y recuerdo que unos gemelos, ;odiosos! ¡Los cabros pesados en segundo medio, se burlaron de la voz, entonces para mí fue chocante, entonces de ahí fue como...! Ahhh... mi voz es lo que a mí me desagrada de mí! Eduardo (28 años)

Lo evidenciado en estas narrativas docentes, refleja cómo la heterosexualidad normativa y hegemónica, contribuye a la construcción de determinados imaginarios ligados al miedo, en la subjetividad de los/as docentes, evidenciándose la exterioridad de la homosexualidad respecto a su otro opuesto, la heterosexualidad. Lo que no hace más que reflejar, la imposición de un ideal de sujeto dedicado/a al ejercicio docente, un sujeto que idealmente cumpla con los requisitos del ser hombre/masculino/heterosexual, o del ser una mujer/femenina/heterosexual. Imposición que repercute incluso, en el rechazo a las características del propio cuerpo

Sin embargo, también hay historias de vida que se fugan de esta colonización heterosexuada de las subjetividades, esto ocurre en algunas ocasiones, cuando la historia personal del/la docente influye en la construcción de lo que aquí llamaré como prácticas de empoderamiento sexual. Estas prácticas, en algunos casos, emergen luego de varios 
años de ejercicio docente, o en otros, se posicionan desde la primera inserción al sistema escolar.

Yo sali de mi casa con toda la verdad por delante y es algo que voy a mantener. Si no les gusta, no les gusta, no tengo porque andar abanderada, pero si no voy a mentir (...) y es una política que me metí, así para mi vida, ¡no mentir más! En algún momento lo hice y fue perjudicial, fue doloroso para mi gente cercana. Simone (25 años)

No llegué con el cartel [al colegio], pero igual se me nota, jamás me he preocupado de ocultarlo (...) sí, iyo no paso piola! y jamás me importo pasar piola, como que para mí nunca fue tema, entonces estuvo ahi y siempre lo ha estado. Millaray, (31 años)

De manera similar, pero a partir de un tránsito, entre lo que se decía temer en un principio (durante los primeros años de ejercicio profesional docente), frente a lo que se dice temer en el presente, se evidencia una migración de los miedos relatados en las biografías de determinados docentes homosexuales y lesbianas. Algunos miedos quedan relegados a un pasado-pisado, pero en otros casos, los miedos solo emergen ante determinadas situaciones y no de manera constante en un cotidiano vivir-se.

\footnotetext{
Ahora no me preocupa tanto el que, si se me nota o no, yo creo que ahora siento que me he validado como profesional, el cómo me han evaluado y el cómo me he presentado en el ambiente laboral, digo ; chuta esto es lo que yo valgo! Al principio, claro era como la imagen, ósea, ningún comentario, me preocupaba mucho eso. En estos momentos igual me preocupa, pero porque quizás les pueden decir a quienes les prestamos el servicio, los niños y más los apoderados. Carlos (31 años)
}

A partir de las citas expuestas, nos encontramos entonces, con dos claras posiciones. Por un lado, algunas historias de vida nos muestran como ciertos sujetos interiorizan los efectos de un poder invisible, un poder de coacción hacia la propia sexualidad. Coacción que como vimos, cada sujeto puede llegar a ejercer sobre sí mismo, debido a que han interiorizado desde su individualidad, la representación hegemónica prohibitiva de la existencia homosexual/lésbica y su consecuente sanción moralizante. Pero, por otro lado, existe la fuga, una fuga movilizada por el rechazo a esta coacción impuesta socialmente a los individuos homosexuales/lesbianas dedicados a la docencia.

\subsection{El Silencio o las diferentes formas de callar(nos): ¿Para qué decirlo si es algo privado?}

La mayoría de biografías docentes recopiladas para esta investigación, hacen referencia a un pánico moral (Weeks, 1998) presente a nivel social, en donde la existencia del/la homosexual/lesbiana dedicado al ejercicio docente, sería identificada como una amenaza a los valores y suposiciones sociales de lo esperado para una persona que se vincula diariamente en la formación de niños/as y/o adolescentes.

Este pánico moral, se traduce en diversos silencios o formas de callar en la escuela. Silencios que en ocasiones son puestos en práctica de manera voluntarista por un/a profesor/a, respecto a dar a conocer o no su existencia como sujeto homosexual o lesbiana. Como también, dichos silencios pueden llegar a ser producidos por la presión social ejercida dentro de la escuela para acallar cualquier tipo de discurso u hecho que ponga en evidencia la sexualidad de un profesor/a gay/homosexual/lesbiana.

Por lo tanto, no hablaremos aquí solo de un tipo de silencio, sino de silencios varios (Sedgwick, 1998), ya que cada profesor/a relata en sus narrativas de vida, diversas formas en que la propia sexualidad (homo/lésbica) es callada o acallada dentro de las escuelas, 
debido al supuesto peligro y/o amenaza que este tipo de sexualidades ejercerían en los demás (especialmente hacia niños/as y adolescentes).

El pánico moral, de esta forma, moldea las subjetividades y posibilidades corporales del individuo. El callar la sexualidad, el omitir, el tener que inventar o aparentar una vida otra cimentada en la heterosexualidad, será utilizado como estrategias de sobrevivencia por muchos docentes homosexuales/lesbianas.

\begin{abstract}
En realidad, yo trato de heteronormarme, porque por ejemplo la otra vez, los chicos me dijeron ¿̇profe, miró a la profe de lenguaje nueva que llego? $\Upsilon$ yo dije ¡Sí, es guapa! $y$ ahí uno tiene que decir lo que se debería (...) pero siempre en los adolescentes, que están así con sus hormonas, que al ver a una mujer se alborotan completamente, y entonces, como a uno lo ven como un par (...) y yo actú lo más normal posible y digo lo que esperarían escuchar los chicos. Carlos (31 años)

Nunca fue un tema, hasta que llegaron las preguntas ïprofe y usted tiene pololo?, tengo pareja, esa era mi aclaración, tengo pareja (...) entonces una [alumna] dijo, johh pareja, como si fuese mujer!... y se mataron de la risa y se fueron y ni siquiera me dejaron aclarar. Simone (25 años)
\end{abstract}

También, los silencios y omisiones, no siempre son constantes y no siempre se ejercen ante la totalidad de sujetos que habitan el territorio escolar. Los silencios a veces se posicionan entre pares (colegas), o a veces solo emergen ante los alumnos/as. Es por ello, que podemos ver que no siempre se está totalmente dentro del closet, como también, no siempre se está totalmente fuera de él.

Dicha situación se rescata de lo comentado por Alan (26 años), quien señaló:

\begin{abstract}
Cuando terminé mi primer reemplazo, encontré un trabajo en Huechuraba, en el sector de la Pincoya, y ahi ya formé un grupo con profesores con los que tenía mayor confianza [...] y les señalé mi homosexualidad. El decirles, fue por el compartir, por la confianza, y a ellas les confesé, y además que ya había un tema con los rumores dentro de la escuela, por mi forma de ser a lo mejor, mira no sé si yo seré discreto, pero quizás había detalles, que a lo mejor me delataban dentro de los mismos profesores o estudiantes. Pero, también sentía un tema de tener un poco de cuidado de hablar de mi orientación sexual, porque igual noté situaciones de discriminación o exclusión, que empecé a sentir por parte de un profe en particular que tenía un cargo directivo. Alan (26 años)
\end{abstract}

El callarse, el silenciar la propia existencia homosexual/lésbica, la plantearemos aquí, no como una mera respuesta ante la sanción moralizante hacia las sexualidades otras, sino que la plantearemos, como un modo de (auto) censurar la propia existencia del sujeto/a homosexual/lesbiana dedicado al ejercicio docente. Este (auto) censurar, es en ocasiones, movilizado por el mismo individuo que es interpelado/a, y en otras, desde un otro/a sobre el individuo lesbiana/homosexual.

El (auto)censurar, estará ligado entonces, al no permitir que la propia sexualidad (homo/lésbica) sea leída por los demás, lo que dependerá también, según quién está siendo interpelado, por quién(es) y el dónde.

Hay chiquillos que, si son más cercanos al tema de la diversidad sexual, porque tienen amigos que lo son, o porque tienen amigos gays o tienen mayor conocimiento, porque ven películas también y entonces, ¡saben que yo soy gay! $\Upsilon$ me tiran hasta tallas, por ejemplo, tengo alumnas que les encanta decirme que me andan buscando pololo, iyo me rio igual de eso! $\Upsilon$ yo les digo, ¿ya pero qué tipo de pololo me vas a buscar tú, si tienes 15 años? Así que yo, como que nunca digo... que si si o que no (...) y me tiran la talla. Por ejemplo, el otro día fue un grupo folclórico al colegio y esa alumna me pregunta... si es que me gustó algún bailarín y yo le dije ¿̇pero de que me estás hablando? (en tono de risa). Entonces, yo no tengo porque asumirlo delante de un alumno, porque al final 
está dentro del plano de lo privado, pero tampoco me voy a alarmar porque me estén molestando con eso. Oscar (32 años)

$A$ veces el tema de la sexualidad, en esos espacios de discusión como consejo de profesores, trato de no tocarlo, para que no digan ;Ahh él es gay y por eso dijo eso! Carlos (31 años)

De esta forma, la (auto) censura no será siempre un continuo, presentando una amplia variabilidad entre el dejarse ver y el ocultarse, entre el estar dentro o fuera del closet o como también vimos, entre el callarse y el confesarse. Este omitirse o (auto) censura, de acuerdo a lo analizado, tiene relación con la separación entre lo que se considera como privado y público. En donde la sexualidad (homosexual/lésbica) estaría dentro del espacio privado, situación que, para algunos sujetos, deberá mantenerse en silencio, debido al carácter público del espacio escolar.

\subsection{Profesor los niños dicen que usted es hueco: Violencias cotidianas dentro del espacio escolar}

El régimen heteronormativo controlará (a veces en mayor o menor medida) las existencias de los profesores homosexuales y lesbianas, los que deberán tener la habilidad de saber con quién visibilizarse o ante quienes no. Esa habilidad se concretará, como bien dijimos, como un mecanismo de sobrevivencia que algunos dicen ejercer en determinados momentos y contextos.

Esas estrategias de sobrevivencia, responden también, a la presión ejercida por lo que llamaré aquí como mandatos reguladores heteronormativos, los que se compondrían por una serie de prácticas, que encarnan determinados sujetos o grupos sobre otros, dentro de la institución escolar, como también, estarán compuestos por determinados discursos contenidos en diversos documentos que algunos sujetos hacen alusión (manuales de convivencia, reglamentos de disciplina y en ocasiones, el mismo currículum escolar).

Estos mandatos reguladores heteronormativos, movilizan una serie de estereotipos y prejuicios que se despliegan en los procesos de socialización dentro del espacio escolar, y que tienen como foco, el silenciamiento o sanción pública moralizante hacia el profesor homosexual o la profesora lesbiana. Como veremos, estos mandatos son perpetuados por diferentes sujetos, en algunos casos serán los propios alumnos/as, en otros, los pares docentes, los directivos, y también, los mismos apoderados.

Me pasó con un curso en particular (...) es bastante, el curso completo es bastante homofóbico en el mismo colegio, han sido formadas con profesoras desde muy chicas, muy conservadoras, como que la crianza igual la fueron adquiriendo y justo yo hago el mea culpa, yo me sentí mal cuando lo hice. Había llegado un profesor nuevo al colegio, que era el profe de educación física, que era así muy tonificado, muy así como grande y andaban todas en marzo vueltas locas por el tipo y tienden de hacer esa manía de juntar a los profes, de hacerlas parejitas y yo andaba atravesada porque ya había tenido un mal momento con una chiquilla, habiamos tenido asi como incumplimiento de algo, me chorié. Entonces llega otra [alumna], me pongo a escribir muy enojada en la pizarra, se habían portado súper mal, entonces ella me dice: "¿profe, le gusta el profe X?”, y yo le dije ¡no!, ¿̨por qué me va a gustar? ¡Porque a todas les gusta po!, pero a mí no me gusta, le respondí, ¿̇cuál es el problema de que a mí no me guste?, chiquillas cuál es su manía de tener que estar juntando a la gente. Pero dígame [alumna] ¿lo encuentra encachado?, ¡no corazón, no me gustan los hombres! y ahí se le cayó la cara, fue a ella sola, y me dice ¿profe es lesbiana? $\Upsilon$ ahí cache que varias se dieron vuelta y le dije ;si! [Ante eso la alumna responde] ;oh que asco! y se fue a sentar, y yo pedí permiso, fui al baño, me calmé y dije iya filo! y seguí la clase, como lo más normal posible (...) me sentí mal, solo por el hecho de haber yo reaccionado de 
mala forma, yo sentí que reaccione mal, que quizás podría haber sido la misma respuesta, pero de otra forma. Simone (25 años)

Pedro (28 años) también relata otro episodio en donde emergen estos mandatos reguladores heteronormativos, no de manera explícita, pero con la misma intención reguladora y sancionadora, indicando:

\begin{abstract}
Después unos cabros de tercero medio, sentía que me tiraban comentarios ipara hueviarme!, un día estaban estos cabros cantando la canción del chabón, "yo estoy saliendo con un chabón" (...) como que reflexione, paso otro día, y saque a uno de la sala, lo saque a habar, le dije, Tomas quiero hablar con usted, le pregunte si tenía algún problema conmigo, le pregunte si hay algo de mí que le moleste, que le pueda conflictuar, y dice ¡no profe! $Y$ le dije ¿̇enserio? ¡Esto es un espacio de confianza!, si de verdad hay algo que le moleste dígamelo, para saber porque, yo he notado que ha habido actitudes tuyas conmigo, que me parecen un poco fuera de lugar (...) nunca dije nada, fue todo protocolar, y ahi el cabro dijo, ¡no profe perdón!, nunca más, lo quiero harto, perdón perdón perdón (...) nunca visibilizamos el tema, si no que fue como códigos. Pedro (28 años)
\end{abstract}

Esta detentación de poder o status de la que se blindan ciertos sujetos y de manera específica, ciertos bio-hombres, respecto a las demarcaciones de lo aceptado/prohibido en términos de masculinidad, se refleja en un episodio de hostigamiento o incluso acoso por parte de un otro par docente, en este caso, unos otros profesores, compañeros de trabajo de Pedro (28 años), quien relató:

\begin{abstract}
Bueno ese primer año de trabajo, había un profe de filosofía que era gay y a mí me gustaba, pero no estaba seguro si era gay (...) lo agregue a Facebook y ahi cache que era gay, nos hicimos amigos y claro, empezaron los demás, porque a él lo cachaban, porque su comportamiento era bien hermético, entonces se especulaba mucho hacia él, cahuines. Habia un club de Toby y los comentarios entre ellos eran bien flaites, ;no este es maraco!, ifleto! y como yo era nuevo, me sume al club de Toby, y no sé, se juntaban a jugar play y cosas que no me gustaban hacer a mí, no me sentía cómodo, y empecé a decir ique lata esta cuestión! porque nunca antes lo había ocultado a mis amigos o familia, era entonces como retroceder a todo. Tome distancia y comencé a conocer más a este tipo de filosofía y nos hicimos re amigos en el colegio, y claro nos empezamos a juntar, almorzábamos juntos y ahí empezaron a molestarnos a los dos y yo soy medio enojón, estábamos almorzando un día cerca del colegio y salen mis colegas, nos ven y nos sacan una foto y lo suben a un grupo de WhatsApp y ponen ;los pololis! Pedro (28 años)
\end{abstract}

Estos mandatos reguladores heteronormativos, se traducirían dentro de las vivencias de los y las docentes homosexuales y lesbianas como crueldades heteronormativas, las que serían situaciones que más que cumplir con los criterios de lo que se podría considerar como episodios de violencia, son situaciones que jugarían un rol clave en la construcción, delimitación y control constante de las fronteras de lo que actualmente se considera como lo normal dentro de la escuela, en relación a la sexualidad y al género de cada quien, generando de acuerdo a lo analizado en las vivencias expuestas aquí, importantes daños y dolores emocionales a quienes las vivencian.

\title{
3.4. La (in)seguridad dentro de un territorio hostil. Entre el empoderamiento sexual y las alianzas con la institución escolar y/o parte de sus miembros
}

Por un lado, se hace evidente a partir de lo analizado, que la presencia de los mandatos reguladores heteronormativos que coaccionan a los cuerpos y subjetividades de los y las docentes homosexuales y lesbianas, impactan en la percepción que ellos/as desarrollan sobre su lugar de trabajo, como un espacio caracterizado por su seguridad y/o inseguridad, respecto a su existencia como sujeto homosexual o lesbiana. Y, por otro lado, 
emergen dentro de las narrativas docentes, la identificación de la escuela como un espacio que refleja las características de la cultura hegemónica, en donde lo que se dice sentir, percibir, creer y vivir, estaría determinado por las características contextuales en las que cada uno/a se ha posicionado (aquí emergen las nociones de capital cultural, clase social, género, edad, entre otras).

Este vivir-se dentro de las escuelas, como profesor homosexual o profesora lesbiana, estará condicionado (en algunas ocasiones) por las nociones de seguridad que se puede percibir o llegar a construir (en alianza con otros) en un espacio escolar determinado. Respecto a esta seguridad, se evidencian dentro de las narrativas docentes, diversos factores que llevarían a cada uno/a, a identificarla (a la seguridad), como un elemento significativo para el desarrollo de su vida profesional (dentro de la escuela) como también personal (fuera de ella).

Así, emerge en algunas narrativas, la figura de un sujeto empoderado sexualmente o no, donde se posiciona un tipo de identidad, alejada del miedo a ser leída o a ser expuesta, frente a unos otros que están dispuestos (pero no siempre), a homo/lesbo-tolerar, o en casos contrarios, a ejercer los mandatos de coacción y regulación heteronormativos sobre un sujeto docente homosexual/lesbiana.

En la U todo el mundo lo sabía, desde mis ex compañeras hasta los profesores de hecho formábamos grupos, no políticos, pero si grupos con los que salíamos a carretear (...) entonces llegue al colegio, a la práctica, y en verdad ya era tan natural para mí que nunca me lo cuestione en nada (...) los practicantes que venían de la $U$ lo sabían y habia un par de profes que eran amigos míos en ese colegio, que nos habiamos conocido en la $U$, que eran generaciones anteriores a mí, entonces también lo sabian. Entonces, no lo encontré así "esto es casi una enfermedad" tengo que encontrar... apoyarme en alguien para sobrevivir respecto a mi sexualidad, no... jera no más! Millaray (31 años)

Yo creo que después, como parte de mi necesidad de sentirme propio en un contexto, ya que al final el trabajo es el mayor tiempo donde yo soy. Entonces yo no puedo vivir inventando una postura (...) Además por el entorno en que te manejai, porque igual yo entre a estudiar artes, me manejo con otra gente (...) No sé, no tengo por ejemplo, amigos ingenieros, casados, con hijos y que me tengan como que esconder de alguien, ¡no po!...en mi familia igual saben...ehh no tengo amigos que tengan ese discurso que yo temo. iEntonces...claro, porque igual tengo “conocidos” que tienen que responder a un círculo de apariencias, entonces yo no po... entonces yo valoro eso, entonces no podría estar en algún lugar de otra forma...! no podría nomas!, duraría dos días y me voy. Andy (31 años)

En virtud de estas vivencias, emerge como factor que contribuiría al establecimiento de la seguridad en el habitar sexual dentro del espacio escolar, el hecho de poder construir relaciones de alianzas o respaldo con las personas que forman parte de la institución en donde se trabaja o trabajó (directivos, docentes, alumnos/as, y en menor medida, apoderados).

Mira es que tuve una vez un problema con un personaje, en el colegio, con un coordinador. Un problema x. Entonces el tipo dentro de su furia me dijo: "acaso me interesa que tú seai un hueon raro" Como diciendo... me dejo ver que yo era "un hueon raro" y yo quede así como, ¿̇qué te pasa? (...). El asunto es que la discusión había sido en un contexto donde había estudiantes, si ese fue el asunto. $\Upsilon$ se acercó el dueño del colegio y me dijo: "el colegio no tiene ese pensamiento, el colegio no piensa eso. Si tú quieres puedes hacer una acusación en el ministerio público hacia esta persona si te sentiste ofendido"... como que ellos me respaldaron. He sentido el respaldo del colegio en ese sentido (...) yo siento ese respaldo, tengo como esa seguridad. Yo creo, por ejemplo, que si estuviera en un colegio donde fuera... me sintiera un poco cohibido, yo 
creo que no continuaría ahí (...) mis colegas dijeron “¿Cómo?...!tu eres así, filo!, y ahi yo me di cuenta que, como para estos hueones, era más importante lo que yo era, de que, no sé, que fuera maricón. Andy (31 años)

Bueno tampoco me afana decir hola soy profesor de historia y soy gay, (...) el que sabe sabe, de los estudiantes y si saben todos, saben todos. Ta como que me da lo mismo, ya pase la valla con algunos estudiantes de que sepan cachay, y yo después de eso como que me relaje mucho, entonces después salió esa generación de cuarto medio y había una alumna mía que éramos bien cercanos y estábamos hablando, le estaba enseñando para la PSU y yo le conté. Le dije jsabi que Javi soy gay!, yo le conté jaja, como que sentí la necesidad de contarle a ella, mi ex alumna y dijo, [respuesta de la alumna mencionada] ¿enserio? ¡Ohh que bacán! (...) y este año hice la misma cuestión, en el mismo contexto, pero ella [alumna] me pregunto. Fue distinto, ahi salió de ella y le dije ¡no Constanza, soy gay!, ;si todos saben para que te haces la lesa!, [ante lo que la alumna le contesta] ino profe Pedro!, „no todos saben! Le conté a esta cabra igual po jajaja y después, en la graduación me decía, gracias por la confianza profe! Pedro (28 años)

Aquí, la voz emerge desde el silenciamiento y la (auto) censura. Aparece un sujeto que expresa la necesidad de visibilizarse, de existir dentro de un espacio. El reconocimiento y visibilidad también son señalados, por lo tanto, como una necesidad para el vivir bien, para el desarrollar un día a día en donde no exista esa presión constante a verse en exposición de manera involuntaria, y a quitarse de encima la carga existente a vivir-se desde el silencio, la (auto) censura o a la invención de una mascarada cimentada en la heterosexualidad. Por lo tanto, y a partir de lo expuesto presente en las citas, no será lo mismo el vivirse dentro del closet, que fuera de él dentro de la escuela.

\subsection{La pedagogización del cuerpo: Prácticas de (a) normalización de las ficciones de masculinidad y feminidad en docentes homosexuales y lesbianas}

La escuela es señalada en las narrativas de los y las docentes, como un espacio en donde se despliegan las normas hegemónicas de género y sexualidad, y también, como un espacio en el que se promueven las representaciones de lo femenino y de lo masculino, en sintonía con la heterosexualidad del deseo. De esta forma, se generará un proceso de pedagogización del cuerpo (Morgade, 2008), proceso en donde todos/as quienes confluyen en la escuela, tendrían que encarnar las normas adecuadas respecto a las conductas permitidas para un hombre y una mujer, exigiéndose, por consecuencia, la encarnación de ciertos ideales de femineidad y masculinidad en los y las docentes (Butler, 2001).

Emerge a partir de ello, la noción de lo esperado, noción que se vuelve fundamental en las historias de vida de los y las profesores/as, debido a que ellos/as, como adultos dentro de la institución, se posicionarían más que en sujetos referentes o facilitadores de un conocimiento disciplinar específico, sino que se volverán (a voluntad o no), en sujetos referentes de un deber ser. Un deber ser a encarnar y a visibilizar, en concordancia con lo que la sociedad y los discursos hegemónicos existentes en ella, determinan como lo esperado/aceptado/normal para una persona dedicada a la docencia escolar.

Así, lo esperado entrará en conflicto directo cuando estas normas de género que se encarnan en los cuerpos de los y las docentes homosexuales y lesbianas, no pueden llegar a ajustarse dentro de los márgenes aceptados/tolerados, debido a que, en ocasiones, no se lograría encarnarlas o reproducirlas a cabalidad (Connell, 2015). Esta dificultad, quedará en evidencia en las narrativas de los/as profesores/as homosexuales y lesbianas, quienes señalan: 
Yo no tengo una voz muy gruesa, entonces igual eso me ha dificultado, o sea yo mismo me creo esa barrera, de decir pucha, mi voz no es tan varonil como yo quisiera [...] tuve que empezar a trabajarlo, por ejemplo, cuando llegaba a clases yo me grababa y no sé, escuchaba la voz... suave, además que he tenido...trabajo en un colegio de riesgo social, entonces he tenido la obligación de subir el tono, manejar la voz, sacar una voz mucho más varonil, sin hacerme el macho, no, no es eso, sino que para tratar de imponer más la voz y que se note más. Eduardo (28 años)

Trabajando con algunas colegas que ya tienen tiempo en el colegio, me decían de que habia un profesor que creo que era de lenguaje y que a él lo echaron, llevaba un año trabajando en la escuela me parece y al él lo echaron y el rumor de pasillo que hizo una inspectora de ese momento, era que él era muy así, que él era "amanerado" y que lo habian echado por que él era muy amanerado. Entonces, a mi igual me dio lata escuchar el comentario, dije joh a lo mejor me puede pasar a mí!, de repente me pueden encontrar que soy un poco tosca. Simone (25 años)

El tema de la homosexualidad fue más un tema de apariencia o de gestos, cosas así que se sabía pero que no se quería decir, pero no me hacía problemas, porque yo con los hombres no me acercaba, en ese colegio yo tenía un curso de hombres, era un tercero medio, pero yo con ese curso no me... fue una cosa de hablar, ni siquiera tocarles el hombro, „nada!, ni siquiera me quedaba en la sala, terminaba la clase y yo me iba al tiro (...) Entonces siempre se rondaba en mi esta cosa media paranoica (...) con las cabras era como súper amable y no quería tener ninguna relación autoritaria y con los cabros era más autoritario. Dimarco (27 años)

Se evidencia, en estas narrativas, el cómo estas heteronormatividades impactan en los cuerpos de los y las docentes, influyendo incluso (en algunos casos) en lo que ellos/as podrán hacer o no a través de sus cuerpos. Así, el comportamiento, la sociabilidad misma que se pueda llegar a desarrollar dentro de la escuela, estará condicionada por las normativas de lo aceptado, lo permitido y lo esperado para un profesor/a de acuerdo a su sexo/género, lo que se irá inscribiendo en sus cuerpos (Bourdieu, 2000; Rich 1996; Wittig, 1992) e irá determinando los límites y posibilidades de sus itinerarios corporales en la escuela.

\subsection{Primero, soy el profesor de historia, comunista y después gay: El olvidar de nuestros cuerpos sexuados en las aulas}

El no situarse dentro del discurso (signado por la resistencia y subversión a existir bajo la heteronorma) se cruza, muchas veces, con el miedo y pánico moral que se percibe o existe en la realidad social del momento. En ocasiones, no se tomará presencia dentro de un discurso (pedagógico), y no se posicionará el hecho que seamos nosotros/as (los y las docentes) sujetos signados por un género y sexualidad (in-estable, en devenir constante, disidente, visibilizados o no). Situación que es necesario evidenciar aquí, debido a que todo tipo de conocimiento se encarna, produce y reproduce en los cuerpos (Alonso y Herczeg, 2013).

Mi objetivo en el colegio, es reivindicar los derechos, no desde mí, sino que desde un punto de vista social, de que es importante que reivindiquemos los derechos de todos, entonces yo hablo de los gays en clases, hablo de la igualdad de derecho, pero siento que no debo mostrarme yo como ejemplo cachay o no, igual hay un filtro, de un contexto escolar conservador, los papás son conservadores (...). No tiene que ser porque yo soy su profesor gay, sino que de todos los gays, quizás lo vuelva más significativo, que yo sea el profe gay, pero tampoco me quiero utilizar como ejemplo para abordar eso. Pedro (28 años)

Cuando estamos viendo que el currículum es abierto, que habla del discurso argumentativo, y dentro de esa argumentación se habla de temas polémicos, pero no se dice cuáles son los temas polémicos, entonces tenemos cierta libertad de poder discutir 
(...) En tercero medio es parte del contenido, sin embargo nunca transparente mi sexualidad ahi, era un discurso que yo traía de la sociedad a la sala y ahí se discutía y cada uno presenta su punto de vista, entonces era mucho más importante ahíplantear la postura que plantear mis vivencias. Oscar (32 años)

El no situarse dentro de un discurso, no es algo generalizable a todos los sujetos, sino que también, se produce todo lo contrario en algunos casos. Sujetos que son sexualmente visibles (fuera del closet) dentro de la escuela, y que han desarrollado prácticas pedagógicas, en donde su cuerpo, su subjetividad y sus experiencias son (ex)puestas dentro de un discurso. Aquí se rompe la norma, se muestran vidas otras, y el modelo y la construcción blanqueada y heteronormada del profesor/a dentro del sistema escolar se desarma, en el sentido de introducir otros cuerpos docentes posibles y visibles. Emergiendo un discurso no separado de la propia experiencia, sino que en constante flujo con ella.

\begin{abstract}
O sea, ya muchas de mis alumnas me han contado que les gusta una compañera, que les gusta una chiquilla, que les gusta un niño y una niña, entonces muchas se aprobleman y me dicen ¿̇profe como lo ha hecho usted?, ¿̇ómo lo hizo usted?, nada, yo les contesto desde mi experiencia y desde lo mucho que, ósea a lo mejor a mí me resulto, a lo mejor el tuyo no, pero también las oriento a que hablen y busquen ayuda si necesitan y que en ese sentido yo igual estoy como dispuesta. Simone (25 años)

Como con los chicos me ha traído más confianza, mas cercanía, como que me ven casi transparente, ;si o sea la profe nos dijo esto, nos dijo que es lesbiana, no nos va a mentir sobre esto otro, si fue capaz de decir esto, no nos va a negar!, de hecho, hay chicos que se acercan a contarme sus problemas. Millaray (31 años)
\end{abstract}

Se evidencia a partir de estas narrativas, que el situarse dentro de un discurso, dar el paso de visibilizar la existencia sexuada, y problematizar el yo con los otros dentro de un contex to pedagógico, ha traído posibles beneficios. Por lo tanto, el exponerse, el situar a una identidad o vivencia sexual de un/a docente homosexual y lesbiana, puede ser o no ser beneficioso, es una apuesta que es necesario descubrir. Aquí, solo evidenciamos quiénes lo han hecho y cómo lo han hecho.

\title{
3.7. Al hacer esto me estoy quemando a lo bonzo: Arriesgando el Yo mediante prácticas pedagógicas que tuercen (queerizan) el currículum
}

Al no haber imágenes y contenidos explícitos en relación a la diversidad de sexualidades y de géneros (fuera del binarismo hombre-mujer) dentro del currículum escolar oficial, emergen en las narrativas de los y las docentes homosexuales y lesbianas, determinados discursos de visibilidad, en donde cada uno/a, desde su propia subjetividad, intentaría problematizar dicha ausencia en las aulas. Así, se corre el lugar de la victimización, de la (auto) censura y se posiciona la desobediencia y agencia de los discursos.

El levantamiento de un tejido individual de rebeldía (Paredes y Guzmán, 2013) ante la heteronormatividad silenciadora, será un tejido, que la mayoría de las veces se dice hacer de manera individual y en solitario, muy pocas veces en comunidad. Así, desde la agencia individual y su movilización hacia lo colectivo, se amplían los horizontes de creatividad y producción pedagógica en los ámbitos de género y sexualidad. Producción que deberá estar siempre atenta a las posibles coacciones y mandatos reguladores de la heteronormatividad escolar.

En lo que es literatura, uno lo puede abordar, pero no está explicitado, por ejemplo tú lo puedes incluir, pero eso tiene que ser modelado por el docente, no está dentro del currículum de lenguaje, pero dentro del aula si se podían dar las conversaciones, porque justo era un tiempo, en este último periodo respecto a las leyes, porque ya estaba el tema del acuerdo de unión civil, ya estaba dentro de la opinión pública el tema de 
matrimonio igualitario y justo me toco hablar del tema del análisis del discurso en tercero medio, y ahi el tema de las relaciones homosexuales se podían conversar de manera abierta. Oscar (32 años)

Enseñando adjetivos, yo les digo, jla misma palabra, que es beautiful, te sirve para decir que alguien es hermoso y es hermosa, no tiene género y por eso yo les digo, me gusta el inglés, la mayoría de las cosas no tiene género! y las chiquillas preguntan, pero ¿̇que significa eso? [yo les digo] que esto mismo lo puedes ocupar para un hombre y para mujer, el inglés no hace la distinción como el español, que es importante eso pos chiquillas, porque a veces tenemos personas que quizás nosotros no tenemos por qué saber, pero a lo mejor hay alguna compañera que algún día puede llegar a esta escuela y a lo mejor la chica es transgénero y les explico. Simone (25 años)

El currículum es señalado como una instancia que se puede torcer (queerizar), en el sentido de modelarlo como dijo Oscar, hacia direcciones en donde ciertas temáticas, silenciadas u omitidas, puedan introducirse. La mayoría de los/las docentes parte de este estudio, indican el generar estos espacios de conversación y problematización hacia dichos silencios. Las estrategias pedagógicas son diversas, hay espacios específicos en donde el currículum posiciona un contexto favorable en donde las temáticas referidas a la amplitud de sexualidades y de géneros pueden introducirse. Pero siempre será desde una intencionalidad individual, desde lo que el docente considere como apropiado a introducir.

El currículum explícito en algunos momentos puede dar oportunidades para problematizar ciertos discursos, pero en las ocasiones en que éste silencia y omite a las vidas de los sujetos LGBTIQ, emergerá, desde lo cotidiano, la introducción y problematización de ciertas temáticas que tuercen y ejercen un poder de acción desde un lugar otro. Un torcer que estará siempre signado por el miedo, un miedo ante lo desconocido y un miedo ante lo no permitido a poder decirse y realizarse en el ámbito pedagógico escolar.

\begin{abstract}
El otro tema fue cuando los llevé [a mis alumnos/as] al museo de la memoria en tercero medio, habían dos apoderados que no querían que sus hijos fueran a un museo comunista y ahí también fui y mostré, el valorar los derechos humanos, yo con el currículum en mano. Eso es como cuando me huevean los apoderados, voy con el currículum, y se los muestro cachay, pero no sé si podría hacer eso con otro tema, y claro, ahí se quedan callaos, pero si allá es un colegio privado, son los clientes, los apoderados son los clientes. Pedro (28 años)
\end{abstract}

En el camino de ejercer su docencia y buscar herramientas que les permitieran ir problematizando ciertas temáticas, los y las docentes señalan que muchas veces la propia formación inicial docente puede actuar como limitante:

Yo puedo abordar ciertos temas, no sé po, que hable de las AFP, el currículum me da eso, pero ya empiezo hablar no sé po, que hay... la teoría queer... no sé, yo tampoco cacho mucho del tema, es algo que no sé tanto tampoco, tiene que ver también con mis conocimientos de profesor disciplinario, con lo que yo sé cómo docente también, con mi formación, ósea yo obviamente me enfoco en lo que yo sé, soy ignorante en esos temas. Pedro (28 años)

\title{
4. Conclusiones
}

De este recorrido y para dar respuesta a la pregunta que guío a esta investigación: ¿Cómo significan las vivencias relacionadas a su propia sexualidad, cuerpo, género, los y las docentes homosexuales y lesbianas que se desempeñan actualmente en contextos educativos escolares, en la ciudad de Santiago de Chile? presentamos a modo de síntesis, los siguientes hallazgos: 
La principal respuesta a dicha interrogante, es a través del miedo. Miedo a lo desconocido, miedo a lo incierto, miedo al cómo ellos/as podrían ser percibidos. Miedo que tiene su origen, en los prejuicios y el pánico moral existentes hacia la figura del sujeto homosexual/lesbiana dentro del actual contexto país. Respecto a ello, los y las docentes que fueron parte de este estudio, señalaron que el miedo es una de las principales consecuencias que tienen en sus vidas dichos prejuicios sociales.

Los docentes indican que existirían discursos antagónicos a nivel social, debido a que por un lado, describen que actualmente han habido cambios positivos ligados hacia una mayor aceptación y tolerancia respecto a los sujetos pertenecientes a la diversidad sexual en el país, siendo la escuela, una institución que supuestamente abogaría y defendería la inclusión de dicha diversidad, pero tal situación sería excluyente, al momento en que un profesor o una profesora sea percibido/a o (auto)identificado como un sujeto homosexual/lesbiana.

En estas circunstancias, el discurso de la tolerancia e inclusión, promovido a nivel social/estatal e introducido supuestamente también en las escuelas, desaparecería, maximizándose los prejuicios y el pánico moral (Sedgwick, 1998), movilizándose toda una carga fantasmática respecto a la sexualidad de los docentes que se perciben o se (auto)definen como homosexuales y lesbianas.

Los miedos deberán incorporarse en el diario vivir, mediante diversas estrategias de (sobre) vivencia que los entrevistados/as señalaron generar para habitar-se en conformidad a lo esperado (Rich, 1996; Wittig, 1992) dentro de las escuelas, obligándoles a tener que adaptarse para vivir dentro de pequeños márgenes de lo habitable.

Los miedos funcionarían como una tecnología de poder (Foucault, 1976) que contribuiría a la construcción de la propia subyugación de nuestros entrevistados/as frente a lo aceptado/permitido por los discursos heteronormativos de la sexualidad que circulan en las escuelas. Subyugación que se traducirá en un continuo moldearse de acuerdo a lo esperado en correspondencia entre su sexo/género y evitar cualquier manifestación errónea entre estos (Llamas, 1998; Morgade, 2008), hecho que evidencia también, como el orden masculino (Bourdieu, 2000) enseña o más bien obliga, a tener que saber cómo comportarse con el propio cuerpo.

Se evidencia que no todos pueden ser sexualmente visibles dentro de las escuelas. La visibilidad dentro de un espacio como este, se alcanza, por un lado, gracias al empoderamiento que se tenga, al nivel de seguridad que se percibe o se llegue a construir dentro de un contexto escolar especifico, como también, a partir del cómo ciertos cuerpos pueden acomodarse de acuerdo a las reglas impuestas por el régimen heterosexual. Así, el habitar en la escuela como sujetos visiblemente sexuados, será a mi parecer, parte de existencias privilegiadas de vida (Guasch, 2000).

La seguridad a tener dentro de una escuela, será fundamental para vivir-se cómo sujetos sexualmente visibles, e influiría en el grado de miedos a tener frente a una posible visibilización voluntaria o involuntaria de la propia sexualidad (sujetos que son sacados del closet a la fuerza o presionados para ello).

La seguridad, como señalé, tiene que ver con el propio empoderamiento personal, pero también, con el contexto en el cual se está habitando, el cual tiene que contar con diversas características. Algunas características, según nuestros entrevistados/as serían, el respaldo y la no discriminación de los pares docentes y administrativos, la sensibilidad 
institucional respecto a la existencia de otros sujetos homosexuales y lesbianas, o (auto)identificados dentro de las territorialidades des-identitarias LGBTIQ en la escuela; la intervención de la comunidad escolar ante casos directos de homofobia hacia ellos/as o hacia otros sujetos; como también, el posicionamiento de un abanico de temáticas vinculadas a la diversidad de géneros y sexualidades dentro del espacio escolar donde se encuentran o se encuentren a futuro (su inclusión en las discusiones de manuales de convivencia, reglamentos escolares, capacitaciones docentes o el desarrollo de actividades escolares).

Respecto a esta seguridad, en las narrativas de los y las docentes que señalan el percibir un mayor respaldo por parte de la institución y de los actores que la integran, manifestaron menores necesidades de invisibilizarse, y son más proclives a abordar temáticas referidas a la diversidad de sexualidades y de géneros dentro del aula de clases o en otros espacios de discusión pedagógica.

Es importante para la mayoría de los docentes participes de la investigación, el reflexionar sobre la propia formación académica, debido a la ausencia que dicen existe hoy, dentro de las mallas curriculares, hacia la inclusión de asignaturas que tengan relación con temáticas referidas a la diversidad de sexualidades, el feminismo y las temáticas queer.

Si bien, algunos/as docentes (minoría) hacen referencia a los avances legales en materia de protección frente a situaciones arbitrarias de discriminación, y en cómo dichas normativas legales, hoy en día, los protegerían ante posibles casos de hostigamiento y discriminación vinculados a su sexualidad. La gran mayoría de los/as docentes, señalaron el vivir-se bajo una constante presión, debido a que la exposición (voluntaria o no) de su sexualidad, puede traer consecuencias inciertas y negativas respecto a su ejercicio laboral.

El resistir o subvertir la heteronorma, no es algo permanente, emerge en determinadas ocasiones, y refleja también, las características de un sujeto consciente de los efectos que tiene la norma heterosexual, en su propia vida y en la del resto, ante lo cual, deciden intencionadamente intervenir, ya sea desde los pequeños espacios de libertad que plantea el currículum o desde su problematización deliberada y voluntarista (tanto en el aula como en otros espacios pedagógicos).

De este recorrido, el vivir-se como profesor(a) homosexual y lesbiana dentro de las instituciones escolares, es algo complejo, debido a los cruces de discursos antagónicos aún existentes a nivel social, lo que se refleja en el hecho de que hoy se dice aceptar o tolerar a las diversas expresiones de sexualidad, pero en la realidad cotidiana, aún seguirían existiendo prácticas de discriminación, hostigamiento, crueldades, y presión social hacia todos aquellos sujetos (auto)identificados o señalados como homosexuales/lesbianas. Pese a ello, es importante destacar aquí, el papel agenciable de los profesores/as, como profesionales que resisten e intentan subvertir los discursos heteronormativos presentes en la escuela. Por lo tanto, cabe recalcar que los/las docentes que fueron parte de este estudio, no fueron prisioneros de la heteronormatividad, sino que fueron capaces de resistir a ella, interpelando a los mecanismos que reproducen las normas hegemónicas de sexualidad y de género en las escuelas.

\section{¿Es posible abrir los caminos hacia el exilio de la heteronormatividad en las escuelas?}

Teniendo en cuenta, de que estamos insertos en una cultura que nos muestra día a día, las características aun presentes de su machismo, misoginia, homofobia y clasismo, considero que el vivir-se como profesor homosexual/lesbiana, independientemente a que se esté 
fuera o dentro del closet, es una realidad compleja y desafiante para quienes la encarnan. La Escuela hoy, y el Estado en su totalidad, se presentan como actores claves en la limitación de las libertades y Derechos Humanos de los sujetos que habitan dentro del contexto educativo escolar. Situación que nos plantea como desafío, y a partir de lo evidenciado en esta investigación, que el currículum oficial actual podría y debería ser pensado como un espacio fundamental para legitimar y validar determinadas prácticas pedagógicas que intenten visibilizar y problematizar la existencia de esos hoy considerados como otros, en relación a su sexualidad y género disidente a la normativa de género hegemónica. Por ello, es necesario que exista una transformación real de lo que hoy se plantea como género y sexualidad dentro del currículum, y por, sobre todo, dentro de La Escuela como institución. En este sentido, considero que el género debiese dejar de entenderse bajo lógicas binarias (centrada en las figuras hombre/mujer), sino que éste, se abra a la amplia gama de posibilidades a existir, las cuales se entrecruzan con categorías de clase, de etnia, de preferencia sexual, de identificaciones de género diversas, de ubicación geográfica, por nombrar solo algunas.

Es importante avanzar en la línea de una Escuela segura y positiva, en donde los estudiantes puedan aprender y los docentes puedan enseñar, en un ambiente cálido y acogedor, libre de intimidaciones y por, sobre todo, sin miedos. En donde los sujetos LGBTIQ no sean abordados como víctimas, sino como agentes, en donde además de las necesidades de los/as estudiantes, se cubran las necesidades del personal, administradores, apoderados, voluntarios que se identifiquen como parte de la diversidad sexual. Cumplir con este objetivo, requiere de un cambio de todo el sistema, que abarque no solo temas curriculares, sino también temas relacionados con políticas públicas, formación docente, evaluación docente, contratación, ascenso, estabilidad laboral, así como las relaciones entre la escuela y la comunidad. Para ello, es fundamental que el Estado se haga cargo de esta realidad poco visible, respecto a las vivencias de los profesores homosexuales/lesbianas, y de todos esos profesores/as cuya sexualidad no es heterosexual, asumiendo de manera responsable y efectiva, los compromisos que en materia de Derechos Humanos ha adscrito con los organismos internacionales.

Hay que avanzar de la misma manera, en la búsqueda de transformar nuestra forma de pensar la sexualidad y el deseo sexual-amatorio, lo que podría ser promovido mediante prácticas pedagógicas legitimadas, que alteren el conocimiento oficial de las disciplinas, que rompan con la heteronormatividad, que busquen historizar los silencios y omisiones del currículum oficial, y que promuevan un entendimiento de opresión como múltiple, interconectado y constantemente cambiante. Por lo que se vuelve necesario, recogiendo las voces de los y las docentes, que se amplíen las imágenes de lo visible en materia de sexualidades y de géneros dentro de la escuela.

Para ello, sería fundamental dotar de contenidos al actual currículum, los textos de estudio, el ordenamiento institucional y sobre todo, la formación inicial y continua del profesorado, teniendo como precaución principal, que en la introducción de ciertas temáticas vinculadas a la diversidad de géneros y sexualidades, no se reproduzca la visión de otredad existente hoy en día a nivel social, como también, el no reflejar las nociones estereotipadas de víctimas hacia los sujetos considerados hoy como LGBTIQ, sino, que sea importante posicionar sus roles agenciables y transformadores a nivel cultural e histórico. Ampliándose así lo visible, para ampliar también lo vivible, dentro de las aulas y espacios escolares. 
Para finalizar, considero que es necesario abrir el tratamiento de la sexualidad como un tema netamente privado, sino que público. Haciendo visible la presencia de la heteronormatividad dentro de la cultura escolar, más allá de la homofobia (que es el resultado de ésta). Hasta el momento, las políticas educacionales han intentado avanzar más en lo último (homofobia y discriminación), sin introducir un cuestionamiento a la naturalización de ciertas temáticas dentro de las escuelas, ni menos en descentrar a la heterosexualidad como principio que fomenta la reproducción de las desigualdades entre las sexualidades (heterosexismo). Para ello, considero que las sexualidades de todos los miembros que componen a las escuelas sean pensadas y abordadas de acuerdo a marcos que permitan su libertad y protección. Por lo que se vuelve necesario que las políticas públicas en materia de educación sexual y de géneros, se abran más allá del binario heterosexual/homosexual. En definitiva, se debiese ir problematizando todo lo que se considera natural y normal (Britzman, 2002) dentro de las escuelas y en los discursos que en ella circulan.

\section{Referencias}

Alonso, B. y Herczeg, G. (2008). Entrar enteras/os/xs a las aulas. Revista Venezolana de Estudios de La Mujer, 31, 5-23.

Butler, J. (1982). Variaciones sobre sexo y género: Beauvoir, Wittig y Foucault. En M. Lamas (Comp.), El género. La construcción cultural de la diferencia sexual (pp. 303-326). Ciudad de México: PUEG.

Butler, J. (2001). El género en disputa. Ciudad de México: Paidós.

Butler, J. (2005). Cuerpos que importan. Buenos Aires: Paidós.

Bourdieu, P. (2000). La dominación masculina. Barcelona: Anagrama.

Bourdieu, P. (2005). Capital cultural, escuela y espacio social. Buenos Aires: Siglo XXI.

Bolívar, A., Domingo, J. y Fernández, M. (2001). La investigación biográfico-narrativa. Enfoque y metodología. Madrid: La Muralla.

Britzman, D. (2002). La pedagogía transgresora y sus extrañas técnicas. En R. Merida (Ed.), Sexualidades transgresoras. Una antología de estudios queer (pp. 197-228). Barcelona: Icaria.

Canales, M. (2006). Metodologías de la investigación social. Santiago de Chile: Ediciones LOM.

Córdova, D. (2011). Teoría queer: Reflexiones sobre sexo, sexualidad e identidad. Hacia una politización de la sexualidad. En D. Córdova, J. Saéz y P. Vidarte (Eds.), Teoría queer. Politicas bolleras, maricas, trans, mestizas (pp. 21- 66). Madrid: EGALES.

Connell, R. (2015). Masculinidades. Ciudad de México: Universidad Autónoma de México.

Esteban, M. (2004). Antropología del cuerpo. Género, itinerarios corporales, identidad y cambio. Barcelona: Ediciones Bellaterra.

Foucault, M. (1976). Historia de la sexualidad. La voluntad del saber. Buenos Aires: Siglo XXI.

Flick, U. (2007). Introducción a la investigación cualitativa. Madrid: Morata.

Flores, V. (2008). Entre secretos y silencios. La ignorancia como política de conocimiento y práctica de (hetero) normalización. Revista de Trabajo Social, 18, 14-21.

Ferfolja, T. (2015). Workplace experience of australian lesbian and gay teachers: findings from a national survey. Canadian Journal of Educational Administration and Policy, 5, 1-35. 
Guasch, O. (2000). La crisis de la heterosexualidad. Ciudad de México: Laertes.

Harding, S. (1987). ¿Existe un método feminista? En S. Harding (Ed.), Feminism and methodology (pp. 57-89). West Lafayete, IN: Indiana University Press.

Haraway, D. (1994). Ciencia, cyborgs y mujeres, la reinvención de la naturaleza. Madrid: Ediciones Cátedra.

King, J. R. (2004). The (im)possibility of gay teachers for young children. Theory into Practice, 43(2), 128-136. https://doi.org/10.1207/s15430421tip4302_5

Llamas, R. (1998). Teoría torcida. Prejuicios y discursos en torno a "la homosexualidad". Madrid: Siglo XXI.

Lecky, D. (2009). Out of the classroom closet: Why only some gay and lesbian teachers are out. Victoria: University Of Victoria.

Morgade, G. (2008). Educación, sexualidades, géneros. Tradiciones teóricas y experiencias en un campo en construcción. En G. Morgade (Comp.), Cuerpos y sexualidades en la escuela. De la "normalidad" a la disidencia (pp. 19-39). Buenos Aires: Paidós.

Movilh, F. (2008). Estudio cuantitativo y cualitativo: Prejuicios y conocimientos sobre orientación sexual e identidad de género en establecimientos educacionales municipalizados de la Región Metropolitana. Recuperado de http://www.movilh.cl/documentacion/ESTUDIOliceos2008.pdf

Paredes, J. y Guzmán, A. (2014). El tejido de la rebeldía ¿Qué es el feminismo comunitario? Comunidad mujeres creando comunidad. La Paz: Comunidad Mujeres Creando Comunidad.

Rubin, G. (1989). Reflexionando sobre el sexo: Notas para una teoría radical de la sexualidad. En V. Carole (Ed.), Placer y peligro: Explorando la sexualidad femenina (pp. 113-190). Madrid: Revolución.

Rich, A. (1996). Heterosexualidad obligatoria y existencia lesbiana. Recuperado de: http://www.mpisano.cl/psn/wpcontent/uploads/2014/08/Heterosexualidad-obligatoriay-existencia-lesbiana-Adrienne-Rich-1980.pdf

Ramos, G. (2007). Escuchando los silencios que instala la heterosexualidad en la escuela. En S. Siderac (Ed.), Educación y género en Latinoamérica. Desafio político ineludible (pp. 34-66). Santa Rosa: Universidad Nacional de la Pampa.

Sedgwick, E. (1998). Epistemología del armario. Barcelona: Ediciones de la Tempestad.

Smith, N. J., Wright, C. M. y Esposito, J. (2008). LGBT educators workplace climate. Recuperado de http://files.eric.ed.gov/fulltext/ED501252.pdf

Tonya, C. (2015). (2015). Doctrinal disciplining of queer educators in Canadian catholic schools. Canadian Journal of Educational Administration and Policy, 7, 9-27.

Wittig, M. (1992). El pensamiento heterosexual y otros ensayos. Barcelona: EGALES.

Weeks, J. (1998). Sexualidad. Buenos Aires: Paidos.

Warner, M. y Berlant, L. (2002). Sexo en público. En R. Mérida (Ed.), Sexualidades transgresoras. Una antología de estudios queer (pp. 99-122). Barcelona: Icaria.

Wright, T. (2010). LGBT educators' perceptions of school climate. Phi Delta Kappan, 91(8), 49-53. 


\section{Breve CV del autor}

\section{Mario Alejandro Catalán Marshall}

Profesor de Historia y Geografía, Universidad de Concepción. Diplomado en Estudios de Género, Desarrollo y Políticas Públicas, Universidad de Chile. Magister en Género y Cultura, Mención Ciencias Sociales, Universidad de Chile (Becario Conicyt). Feminista y activista LGBTIQ, con publicaciones vinculadas a feminismos, estudios de género y decolonialidad (Revista RevIISE-Universidad de San Juan, Argentina y Revista Al Sur de Todo-Universidad de Chile). Actualmente, miembro del comité de Historia y Ciencias Sociales del Departamento de Medición, Evaluación y Registro Educacional (DEMRE) de la Universidad de Chile. ORCID ID: 0000-0002-3875-109. Email: pedhistoriamario@gmail.com 